\title{
Erratum: Wheelchair services and use outcomes: A cross-sectional survey in Kenya and the Philippines
}

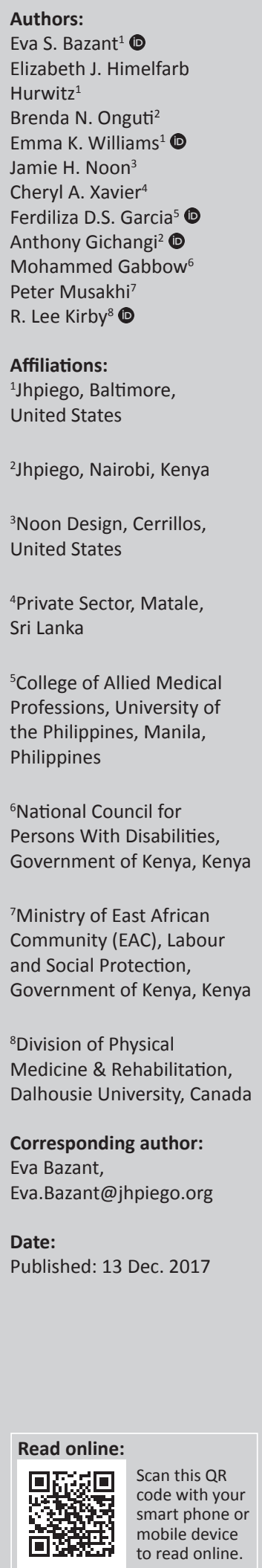

In the version of this article initially published, a sentence which appeared in the abstract needs to be corrected. The sentence reads 'Conclusion: Select services that were associated with some better wheelchair use outcomes and should be emphasised in service delivery' and should read 'Conclusion: Select services were associated with some better wheelchair use outcomes and should be emphasised in service delivery.' This correction does not alter the study's findings of significance or overall interpretation of the study results. The publisher apologises for any inconvenience caused.

How to cite this article: Bazant, E.S., Himelfarb Hurwitz, E.J., Onguti, B.N., Williams, E.K., Noon, J.N., Xavier, C.A., Garcia, F.D.S., Gichangi, A., Gabbow, M., Musakhi, P. \& Kirby, R.L., 2017, 'Erratum: Wheelchair services and use outcomes: A cross-sectional survey in Kenya and the Philippines', African Journal of Disability 6(0), a468. https://doi.org/10.4102/ajod.v6i0.468

Copyright: (c) 2017. The Authors. Licensee: AOSIS. This work is licensed under the Creative Commons Attribution License.

Note: DOI of original article: https://doi.org/10.4102/ajod.v6i0.318 